\title{
Sistem Pakar Untuk Mengidentifikasi Hama Dan Penyakit Pada Tanaman Apelmenggunakan Metode Dempster Shafer
}

\author{
Muhammad Rizky Iman Permana ${ }^{* 1}$, Yufiz Azhar ${ }^{2}$, Otto Endartoi ${ }^{3}$ \\ 1,2,3 Teknik Informatika/Universitas Muhammadiyah Malang \\ rzky.iman@gmail.com¹, yufis@umm.ac.id², endarto11@gmail.com³
}

\begin{abstract}
Abstrak
Pada penelitian ini, dilakukan identifikasi dari serangan hama dan penyakit pada tanaman apel pada dengan studi kasus di Balitjestro. Permasalahan yang dihadapi adalah sulitnya menentukan informasi hama atau penyakit yang menyerang pada tanaman apel yang harus menemui seorang pakar secara langsung, hal tersebut memerlukan waktu yang lama dan memerlukan biaya. Tujuan dari penelitian ini adalah mempercepat mendapatkan informasi hasil identifikasi dari serangan hama dan penyakit pada tanaman apel beserta solusinya tanpa harus menemui seorang pakar. Jenis hama dan penyakitnya yaitu pada hama terdapat Kutu Hijau, Tungau, Trips, Ulat Daun, Serangga Penghisap Daun, Ulat Daun Hitam dan Lalat Buah. Pada penyakit terdapat Embun Tepung, Bercak Daun, Jamur Upas, Kanker dan Busuk Buah. Dari data hama dan penyakit, semua data gejala berjumlah 38 data. Untuk mendapatkan informasi tersebut, dibuatlah Sistem Pakar. Sistem pakar pada penelitian ini untuk menentukan hasil identifikasi menggunakan metode perhitungan Dempster Shafer. Demster Shafer merupakan salah satu teori matematika yang digunakan untuk melakukan suatu pembuktian yang didasari dengan fungsi kepercayaan dan juga logika masuk akal. Pada tahap pengujian menghasilkan nilai akurasi sebanyak $100 \%$. Namun ada salah satu pengujian dari pakar hanya menghasilkan satu dan hasil dari sistem menunjukkan lebih dari satu. Akan tetapi salah satu hasil yang diberikan oleh sistem sama dengan hasil yang diberikan oleh seorang pakar, maka hal tersebut dibenarkan.
\end{abstract}

Kata kunci: Sistem Pakar, Hama dan Penyakit, Tanaman Apel, Dempster Shafer

\begin{abstract}
In this study, the identification of pest and disease attack on apple plant on with case study in Balitjestro. The problem faced is the difficulty of determining the information of pests or diseases that attack on apple plants that must meet an expert directly, it takes a long time and cost. The purpose of this study is to accelerate the information obtained from the identification of pests and diseases of the apple plant and its solution without having to meet an expert. Types of pests and diseases that is in pests are Green Lice, Mites, Trips, Leaf Cats, Leaf Sucking Insects, Black Leaf Caterpillars and Fruit Flies. In the disease there are Flour Powder, Leaf Spot, Upas Mushroom, Cancer and Rotten Fruit. From pest and disease data, all symptom data is 38 data. To get the information, made Expert System. Expert system in this study to determine the results of identification using Dempster Shafer calculation method. Demster Shafer is one of the mathematical theories used to perform a proof that is based on the function of trust and also logic makes sense. At the test stage yields an accuracy value of $100 \%$. However, there is one test of the expert only producing one and the results of the system show more than one. But one of the results given by the system is the same as the result given by an expert, then it is justified.
\end{abstract}

Keywords: Expert System, Pest and Diseases, Apple Plant, Dempster-Shafer.

\section{Pendahuluan}

Apel yaitu suatu tanaman yang berbuah musiman yaitu satu tahun sekali. tanaman ini mempunyai asal daerah pada benua Asia bagian Barat yang memiliki iklim sub tropis. Tanaman apel pertama kali dibudidayakan didaerah Indonesia pada tahun 1934 sampai sekarang dan tanaman ini sangatlah bagus berkembang serta tumbuh di dataran tinggi. Tepatnya di Jawa Timur pada daerah Kota Batu adalah pusat produksi apel yang terkenal di Indonesia. Sejak tahun 1950 di daerah ini apel telah diusahakan, dan pada tahun 1960 hingga saat ini produksi apel sangatlah pesat [1]. 
Musuh dari tanaman apel ini juga sama dengan tanaman-tanaman lain pada umumnya yaitu hama dan penyakit. Penuruan mutu lahan pada pertanian apel di Kota Batu salah satu faktornya adalah serangan dari hama dan penyakit. Pernyataan tersebut didapat dari hasil penelitian Balai Penelitian Tanaman Jeruk dan Subtropika. Ketika tanaman apel terserang hama dan penyakit para petani pun bingung mau memberikan penanganan pada tanaman apelnya bagaimana, ada yang mau mencari solusinya ke pada pakar, sedangkan pakar sangat sulit untuk ditemui ketika kita memerlukan secara mendadak. Banyak sekali dari orang-orang yang tidak mempunyai pengetahuan dibidang hama dan penyakit apel telah bertanya ke tetangga ataupun juga pada sesama petani apel namun juga jarang sekali menemukan jawaban untuk menanggulangi serangan hama dan penyakit tersebut, untuk bertanya kepada pakar tanaman apel juga harus mempunyai janji jauh-jauh hari dulu baru bisa bertemu. Hal seperti itu membutuhkan waktu yang lama juga dibandingkan jika kemampuan seorang pakar dijadikan sebuah sistem yang dapat menentukan suatu serangan hama atau penyakit pada tanaman apel pada sebuah komputer. Oleh karena sebab yang diterangkan diatas dapat disimpulkan bahwa penelitian ini akan membangun sebuah sistem pakar yang berbasis web yang mempunyai kemampuan menentukan serangan hama atau juga penyakit pada tanaman apel dengan cara memilih beberapa gejala yang terlihat oleh petani pada suatu tanaman apel.

Saat ini teknologi berperan penting didalam kehidupan kita, semua yang kita lakukan berhubungan dengan teknologi dijaman kita sekarang ini yaitu tidak akan terlepaskan dari yang namanya teknologi komunikasi. Dari yang terlihat. Kemampuan manusia dalam hal mengingat sesuatu terdapat batasan, sebaliknya dari kemampuan yang dimiliki sebuah komputer dalam hal menyimpan sebuah informasi dan sebagainya lebih akurat ketika komputer menyampaikan informasi tersebut kepada manusia dibandingkan manusia itu sendiri. Dengan mengumpulkan beberapa informasi tentang gejala-gejala, hama dan penyakit serta solusi dari serangan tersebut, komputer dapat menentukan tanaman tersebut terserang oleh hama atau penyakit tertentu beserta sebuah solusi untuk menangani serangan tersebut layaknya seperti seorang pakar.

Berdasarkan kemajuan teknologi dalam bidang teknik informatika, sesuatu kerumitan didalam pengambilan sebuah keputusan yang sebelumnya membutuhkan seorang pakar akan lebih mudah ditanggulangi dengan sebuah sistem yang memberikan hasil tingkat keakurasian lebih tepat dibandingkan seorang pakar. Pada sistem ini juga memberikan informasi tentang solusi yang akan dilakukan agar hama dan penyakit bisa dicegah secara cepat. Teknik yang digunakan didalam sistem pakar ini adalah dengan menggunakan metode perhitungan Dempster Shafer.

\section{Metodelogi Penelitian}

\subsection{Metode Waterfall}

Metode penelitian sistem yang akan dipilih di tahap ini yaitu metode waterfall. Pengertian Metode Waterfall, waterfall sendiri mempunyai arti sebagai air terjun. Metode ini juga sering disebut dengan siklus hidup klasik (classic life cycle). Pada pengembangan sebuah perangkat lunak dapat melalui tahapan yang berurutan dimulai dengan tahapan perencanaan atau planning, permodelan atau modeling, konstruksi atau construction yaitu susunan suatu bangunan sistem, serta menyerahkan sistem kepada pelanggan atau disebut dengan deployment, dan juga diakhiri dengan suatu dukungan pada sebuah perangkat lunak lengkap dihasilkan [2]. Metode waterfall mempunyai tahapan seperti Gambar 1 [3].

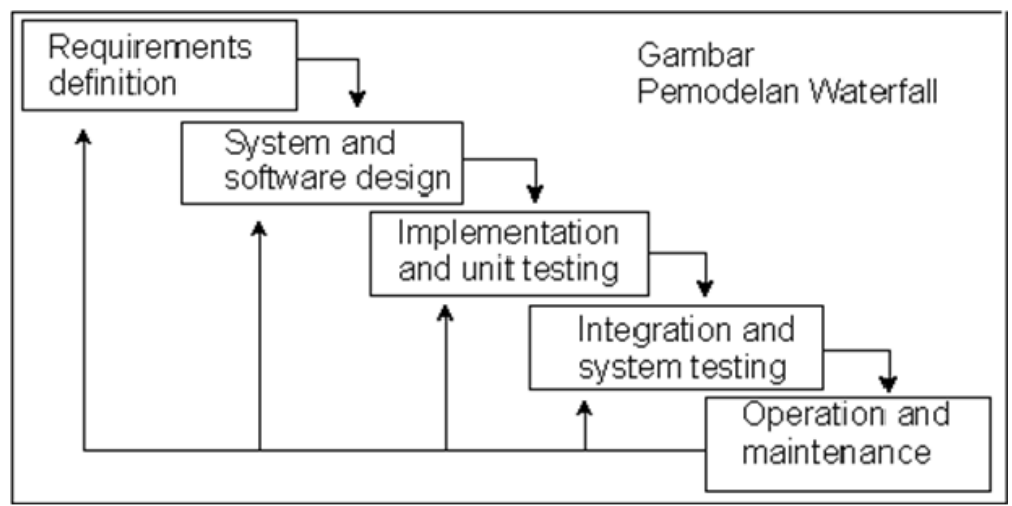

Gambar 1. Tahapan Metode Waterfall

REPOSITOR, Vol. 2, No. 1, Januari 2020: 53-66 


\subsection{Sistem Pakar}

Sistem pakar dapat diartikan sebagai sistem yang mengadopsi cara berpikir manusia yang diterapkan kedalam sebuah komputer untuk menentukan hasil suatu keputusan seperti layaknya seorang pakar. Menirukan cara kerja seorang pakar untuk menyelesaikan masalah dengan menentukan keputusan dalam suatu masalah, itulah tujuan dari sistem pakar [4].

Menurut Arhami, sistem pakar yaitu sebuah komputer yang kemampuannya dalam pengambilan sebuah keputusan sama dengan seorang pakar. Pada pengetahuan yang dimiliki seorang pakar, dapat diterapkan dalam sebuah komputer yang berguna untuk pemecahan masalah-masalah yang dihadapi manusia. Hal ini diterapkan diberbagai bidang seperti contohnya dalam perhitungan matematika, dibidang teknik, pada bidang kedokteran, serta ilmu pengetahuan lainnya. Walaupun kerja komputer lebih baik dibandingkan manusia, akan tetapi kita juga masih memerlukan kinerja dari manusia yang kemungkinan juga komputer mempunyai batasan kemampuan [5].

\subsection{Dempster Shafer}

Teori Dempster Shafer merupakan teori yang membahas tentang penanganan dalam berbagai suatu kemungkinan yang dapat dikombinasikan pada suatu fakta tertentu. Dari DST atau Dempster Shafer Theory tersebut mempunyai permasalahan yaitu konflik yang dapat dipersatukan dengan berbagai informasi yang ada.kumpulan informasi yang saling berbeda dapat diberikan symbol sebagai $q$ atau theta [5].

Sebuah teori yang menjelaskan tentang teori matematika untuk melakukan pembuktian yang didasari oleh fungsi kepercayaan dan juga logika yang masuk akal, yang digunakan untuk menyatukan beberapa bukti untuk menghasilkan kemungkinan dari suatu peritiwa. Pengembang dari teori ini adalah Arthur P. Dempster dan Glenn Shafer. Pada umumnya teori Dempster-Shafer ditulis dalam sebuah interval Persamaan 1.

\section{[Belief, Plausibility]}

Belief (Bel) mempunyai arti yaitu ukuran kekuatan dari bukti dalam mendukung suatu himpunan yang dapat dinilai benar ataupun salah. Jika bernilai 0 mengindikasikan bahwa tidak ada bukti yang kuat, dan Palusibility (PI) jika bernilai 1 manunjukkan adanya nilai kepastian. Palusibility diterapkan sebagai Persamaan 2.

$$
P I(s)=1-\operatorname{Bel}(\sim s)
$$

Jika memiliki keyakinan $\sim s$ maka dikaitkan maka $\operatorname{Bel}(s)=1$ dan $\operatorname{Pl}(\sim s)=0$.

Pada teori Dempster-Shafer dikenal adanya frame of discernment yang dinotasikan dengan $q$ yang disebut dengan "theta". Frame ini merupakan semesta pembicaraan dari sekumpulan hipotesis [6].

Apabila diketahui $x$ adalah sub-set dari $q$, dengan symbol $m_{1}$ sebagai fungsi densitasnya, dengan $y$ juga merupakan sub-set $q$ dengan $m_{2}$. Maka kombinasi densitas dari $m_{1}$ dan $m_{2}$ menghasilkan densitas $m_{3}$, yaitu dengan Persamaan 3 .

$$
m_{3}(Z)=\frac{\sum_{X \cap Y=Z} m_{1}(X) \cdot m_{2}(Y)}{1-\sum_{X \cap Y=\varnothing} m_{1}(X) \cdot m_{2}(Y)}
$$

\subsection{MySQL}

MySQL yaitu sebuah software yang memiliki sistem manajemen untuk database yang biasanya disebut dengan RDBMS atau Relational Database Management System hal ini dsangat dikenal sekali oleh para programmer web. Terutama lagi dalam ruang lingkup linux yang menggunakan script PHP dan juga perl. pada sistem windows sekarang juga tersedia platformnya[7].

Haris Saputro memberikan pendapat tentang MySQL yaitu server dari database yang melakukan proses pendataannya pada suatu serverdengan akses yang tidak terbatas. Makases dapat dilakukan dimana saja dalam cacatan asal terhubung dengan server [8]. 


\subsection{Hama dan Penyakit Tanaman Apel}

Ada tujuh macam hama dan lima macam penyakit yang menyerang pada tanaman apel beserta gejalanya [9]. Dibawah ini adalah beberapa hama yang menyerang tanaman apel sebagai berikut:

a. Hama Kutu Hijau (Aphis Pomi Geer)

Ada beberapa gejala yang timbul apabila tanaman apel diserang oleh hama kutu hijau seperti pada bawah tunas dan daun terdapat kutu berwarna hijau kekuningan, pertumbuhan tunas dan daun terhambat, daun lebih kecil, daun mengeriting, daun rontok dan tinggal rantingnya saja.

Solusi dari serangan hama ini yaitu mengatur jarak tanaman jangan terlalu rapat agar setiap tanaman tidak bersentuhan antara pohon satu dengan yang lainnya, melakukan penyemprotan menggunakan bahan aktif Metidation dan Imidakloprid sesuai dengan anjuran pemakaian.

b. Tungau (Panonychus Ulmi)

Gejala dari tanaman apel jika terserang oleh hama tungau ini seperti daun terdapat tungau berwarna merah kecokelatan, daun berbercak kuning, buram dan cokelat, buah mempunyai bercak berwarna cokelat dan berwarna keperak-perakan.

Solusi dari serangan hama ini dengan menggunakan musuh alaminya yaitu coccinellida()e dan lycosa, melakukan penyemprotan menggunakan Akrisida dengan nama bahan aktif Propargite sesuai dengan anjuran pemakaian.

c. Thrips (Thrips Sp.)

Gejala dari tanaman apel jika terserang oleh hama thrips ini seperti daun muda terdapat hama trips muda berwarna kuning, dewasa berwarna cokelat kehitam-hitaman, daun berbintik-bintik putih, kedua sisi daun menggulung ke atas dan menebal, daun pada ujung tunas menjadi cokelat, kering dan gugur, buah mempunyai bercak berwarna cokelat.

Solusi dari serangan hama ini yaitu menyemprotkan menggunakan Insektisida dengan nama bahan aktifnya adalah Methomyl dan Fention sesuai dengan anjuran pemakaian, secara mekanis juga dapat ditangani dengan membuang telur-telur yang terdapat pada daun dan juga menjaga agar lingkungan pucuk tanaman tidak terlalu rapat.

d. Ulat Daun (Spodoptera Litura)

Gejala dari tanaman apel jika terserang oleh hama ulat daun seperti pada daun terdapat ulat berwarna hijau dengan garis berwarna abu-abu pada tubuhnya, daun terlihat transparan, tinggal tulang-tulangnya saja, daun tergerek, dan daun berlubang-lubang tidak teratur.

Solusi dari serangan hama ini dengan menyemprotkan menggunakan bahan aktif Metamidofos dan Monocrotofos, serta secara mekanis dengan membuang telur-telur yang terdapat pada daun.

e. Serangga Penghisap Daun (Helopeltis Sp)

Gejala dari tanaman apel jika terserang oleh hama serangga penghisap daun ini seperti pada daun terdapat serangga, badannya berwarna orange dan sayapnya terdapat sedikit warna hitam, daun berbercak cokelat, daun pada ujung tunas menjadi cokelat, kering dan gugur, buah berbercak berwarna cokelat.

Solusi dari serangan hama ini dengan penyemprotan Insektisida seperti nama bahan aktifnya Metomyldan BPMC. Secara mekanisnya yaitu dengan melakukan penggondrongan atap plastik atau pembelongsongan buah.

f. Ulat Daun Hitam (Dasychira Inclusa Walker)

Gejala dari tanaman apel jika terserang oleh hama ulat daun hitam ini seperti pada daun terdapat ulat kecil berwarna hitam berkoloni dibawah daun, daun terlihat transparan, tinggal tulang-tulangnya saja, dan daun berlubang-lubang tidak teratur.

Solusi dari serangan hama ini adalah dengan cara menyemprotkan Insektisida yang nama bahan aktifnya yaitu Monocrotofos dan Lamda Sihalotrin Sesuai dengan anjuran pemakaian. Secara mekanis dengan melakukan membuang telur-telur yang biasanya menempel dibawah daun.

g. Lalat Buah (Rhagoletis Pomonella)

Gejala dari tanaman apel jika terserang oleh hama lalat buah ini seperti pada buah terdapat lalat dengan kepalanya berwarna cokelat muda, badan berwarna hitam, sayapnya bercorak hitam dan putih, buah terlihat tusukan berwarna putih, buah berbercak kecil berair warna coklat muda, buah membusuk dan buah-buahan gugur. 
Solusi dari serangan hama ini adalah dengan melakukan penyemprotan menggunakan Insektisida nama bahan aktifnya yaitu Fenthion sesuai dengan anjuran pemakaian. Bisa juga membuat tiruan lalat jantan dengan meneteskan Methyl eugenol pada kapas dan kapas tersebut dimasukkan kedalam botol bekas air mineral kemudian digantung dengan ketinggian 2 meter.

h. Embun Tepung (Podosphaera Leucoticha)

Gejala dari tanaman apel jika terserang penyakit embun tepung ini seperti daun berbintikbintik putih, tunas tumbuh tidak normal, daun lebih kecil, daun gugur, tinggal ranting dan buah mempunyai bercak berwarna cokelat.

Solusi dari serangan penyakit ini adalah menyemprotkan Fungisida dengan nama bahan aktifnya yaitu Bupirimate sesuai dengan anjuran pemakaian. Kemudian dilakukan pemangkasan pada tunas atau pada bagian yang sakit serta dibakar.

i. Bercak Daun (Marssonina Coronaria J.J. Davis)

Gejala dari tanaman apel jika terserang penyakit bercak daun ini seperti daun berbintikbintik putih, pada daun timbul serbuk berwarna hitam, kemudian daun berwarna cokelat menjadi kering, daun berlubang-lubang tidak teratur, dan sebagian daun gugur.

Solusi pada serangan penyakit ini dengan melakukan penyemprotan menggunakan Fungisida dengan bahan aktif Klorotalonil atau dengan bahan aktif Mancozeb dan Karbendazim penggunaan sesuai dengan anjuran pemakaian. Secara mekanis dilakukan dengan mengatur jarak tanam antar tanaman agar tidak terlalu rapat, bagian yang terserang dibuang dan dibakar.

j. Jamur Upas (Cortisium Salmonicolor Ber et Br)

Gejala dari tanaman apel jika terserang penyakit jamur upas ini seperti terdapat bintikbintik putih pada permukaan kulit tanaman, terdapat kerak berwarna merah jambu, setelah tua menjadi lebih muda atau putih pada batang, Terdapat bintik atau bulatan kecil berwarna merah tua pada sisi yang telah busuk dan kering, batang mengering, kulit kayu dibawah kerak busuk dan kering, dan daun berwarna kuning dan layu.

Solusi dari serangan penyakit ini dengan dengan mengurangi kelembapan kebun, menghilangkan bagian tanaman yang sakit.

k. Kanker (Botryosphaeria Sp.)

Gejala dari tanaman apel jika terserang penyakit kanker ini seperti batang atau cabang mengeluarkan cairan, batang atau cabang busuk berwarna coklat kehitam-hitaman, buah berbercak kecil berair warna coklat muda dan buah-buahan gugur.

Solusi dari serangan penyakit ini dengan melakukan pengerokan pada batangyang sakit kemudian diolesi menggunakan Fungisida dengan bahan aktif Benomyl dan Propinep Sesuai dengan anjuran pemakaian. Dan bisa juga dengan cara tidak memanen buah terlalu masak, mengurangi kelembapan pada kebun serta memangkas atau membuang bagian yang sakit.

I. Busuk Buah (Gloeosporium Sp.)

Gejala dari tanaman apel jika terserang penyakit busuk buah ini seperti Buah berbercak kecil berwarna kehijauan berbentuk bulat, buah terdapat bintik orange dan juga ada berbintik hitam, buah bebercak warna cokelat dan buah menjadi busuk.

Solusi dari serangan penyakit ini dengan menyemprotkan bahan aktif Benomyl sesuai dengan anjuran pemakaian. Bisa juga dengan tidak memetik buah terlalu masak.

\subsection{Flowchart Sistem}

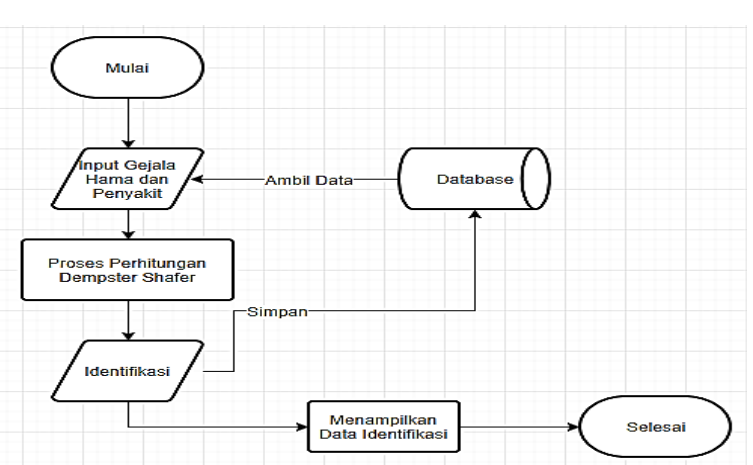

Gambar 2. Flowchart Program 
Flowchart pada sistem pakar ini menjelaskan tentang proses berjalannya program, dimana admin memasukkan gejala yang dialami oleh tanaman apel, hama dan penyakit serta solusi untuk mengatasi hama dan penyakit tersebut. Setelah itu pengguna memilih gejala yang dialami oleh tanaman apel untuk melakukan identifikasi. Selanjutnya pada Gambar 2 menunjukkan akan muncul hasil identifikasi serta solusi untuk menanggulangi hama atau penyakit yang menyerang tanaman apel tersebut. Hasil identifikasi bisa dicetak pada menu laporan.

\subsection{Use Case Diagram}

Struktur menu pada aplikasi sistem pakar dirancang khusus pada web menggunakan bahasa pemrograman PHP. Diagram use case mendiskripsikan sebuah interaksi antara satu atau lebih aktor dengan sistem yang akan dibuat [10]. Berikut Use Case Diagram aplikasi dapat dilihat pada Gambar 3.

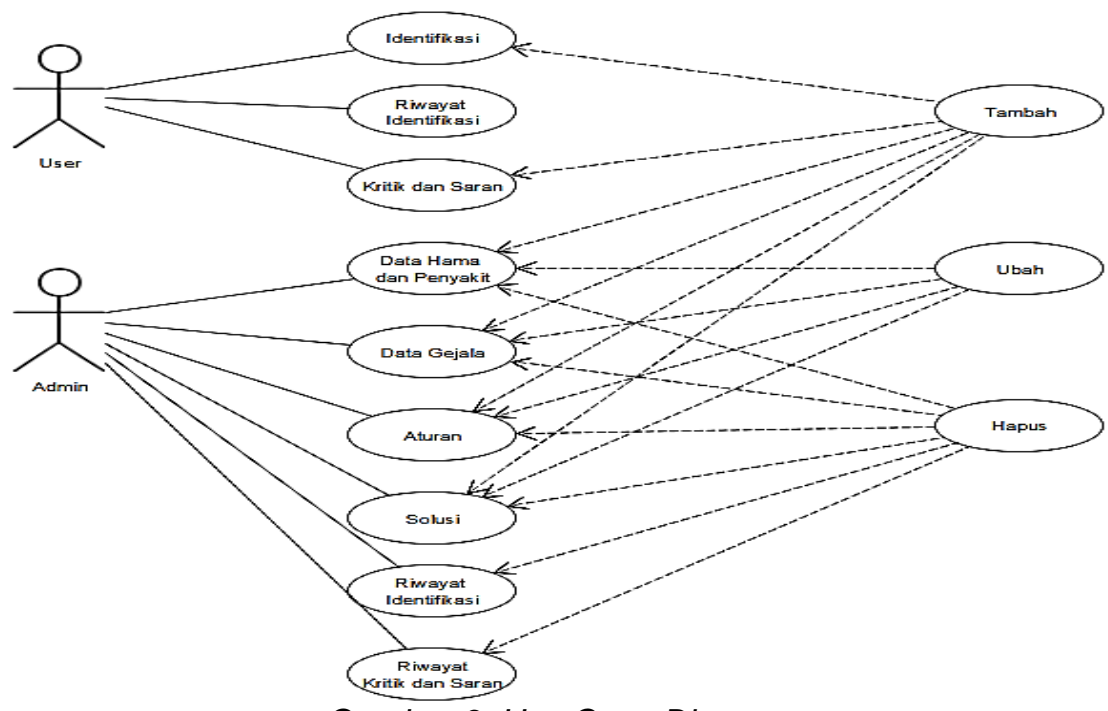

Gambar 3. Use Case Diagram

\subsection{Diagram Konteks}

Diagram konteks yaitu diagram yang menggambarkan suatu ruang lingkup dari sebuah sistem yang dibangun. Sistem ini mempunyai gambaran proses sistem digambarkan dengan diagram konteks Gambar 4 di bawah ini.

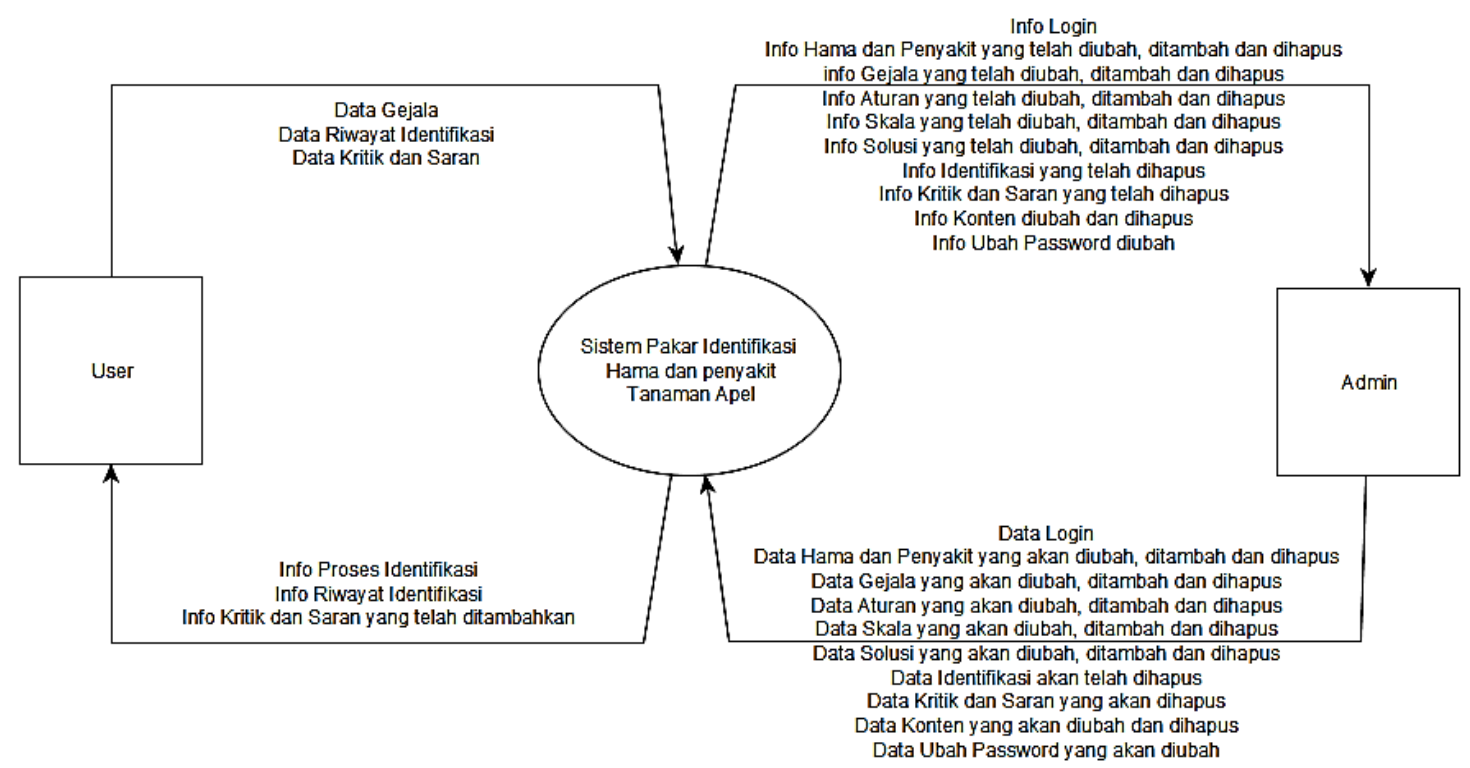

Gambar 4. Diagram Konteks

REPOSITOR, Vol. 2, No. 1, Januari 2020: 53-66 


\subsection{Pohon Keputusan}

Pohon keputusan pada Gambar 5, merupakan sebuah perancangan dimana untuk mempermudah mencari suatu solusi dengan menentukan gejala yang dipilih sebelumnya. Dari susunan tersebut, akan mempermudah dalam menentukan hama atau penyakit apa yang menyerang pada tanaman apel.

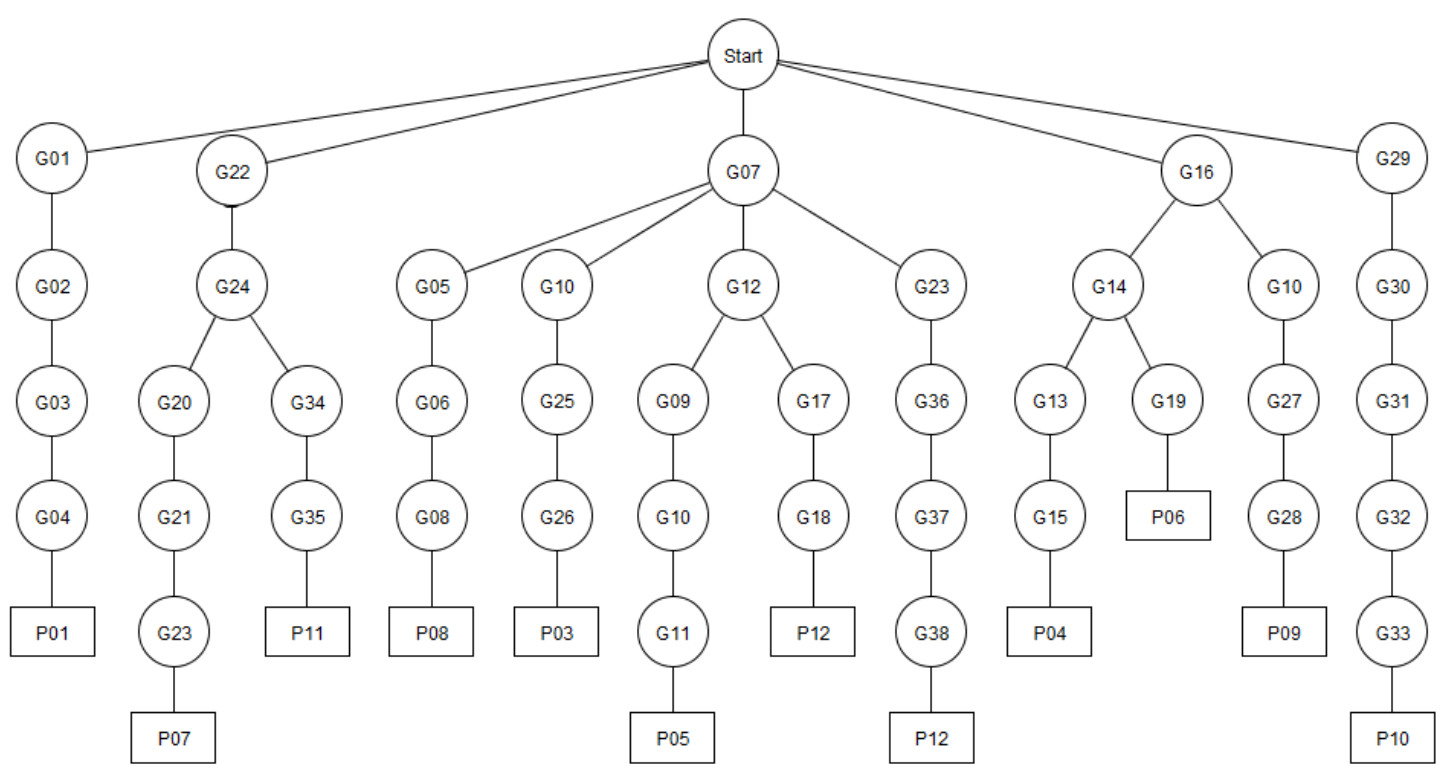

Gambar 5. Pohon Keputusan

\section{Hasil dan Pembahasan}

Pemodelan sistem pakar mengidentifikasi hama dan penyakit pada tanaman apel menggunakan metode Dempster Shafer terdiri dari data hama dan penyakit, data gejala, rule dan juga proses perhitungan dengan metode dempster shafer diambil satu jenis hama dan penyakit, disini diambil contohnya yaitu perhitungan terhadap serangan hama kutu hijau beserta gejalanya.

\subsection{Perhitungan Dempster Shafer}

Perhitungan mengidentifikasi hama dan penyakit pada tanaman apel dengan menggunakan metode dempster shafer adalah sebagai berikut:

Diasumsikan gejala yang dipilih adalah gejala yang terdapat pada tanaman apel. Berikut contoh perhitungan secara manual dengan menggunakan metode Dempster Shafer: Ada beberapa gejala dari Kutu Hijau (Aphis pomi Geer) yang menyerang pada tanaman apel, seperti pada Tabel 1.

Tabel 1. Gejala Kutu Hijau

\begin{tabular}{llc}
\hline Kode & \multicolumn{1}{c}{ Gejala } & Bobot \\
\hline G01 & Pada bawah tunas daun terdapat kutu berwarna hijau kekuningan & 0.2 \\
G02 & Pertumbuhan tunas dan daun terhambat & 0.4 \\
G03 & Daun menjadi lebih kecil dan mengeriting & 0.6 \\
G04 & Daun rontok, tinggal ranting & 0.8 \\
\hline
\end{tabular}

Penyelesaian:

Gejala 1 (G01= Pada bawah tunas daun terdapat kutu berwarna hijau kekuningan): $m_{1}\{P 01\}=0,2$

$m_{1}\{\theta\}=1-0,2=0,8$

Gejala 2 (G02= Pertumbuhan tunas dan daun terhambat):

$m_{2}\{P 01\}=0,4$

$m_{2}\{P 01\}=1-0,4=0,6$

Menghitung kembali nilai densitas baru untuk setiap himpunan bagian fungsi dengan fungsi densitas $m_{3}$. Aturan kombinasi untuk $m_{3}$ seperti Tabel 2 . 
Tabel 2. Fungsi Densitas $m_{3}$

\begin{tabular}{ccc}
\hline & $m_{2}\{P 01\}=0,4$ & \\
$m_{1}\{P 01\}=0,2$ & $\{P 01\}=0,08$ & $m_{2}\{\theta\}=0,6$ \\
$m_{1}\{\theta\}=0,8$ & $\{P 01\}=0,32$ & $\{\theta\}=0,48$ \\
\hline
\end{tabular}

Kemudian dengan menggunakan Persamaan 1.

$$
m_{3}(Z)=\frac{\sum_{X \cap Y=Z} m_{1}(X) \cdot m_{2}(Y)}{1-\sum_{X \cap Y=\theta} m_{1}(X) \cdot m_{2}(Y)}
$$

Maka:

$m_{3}(P 01)=\frac{0,08+0,32+0,12}{1-0}=0,52$

$m_{3}(\theta)=\frac{0,48}{1-0}=0,48$

Gejala 3 (G03= Daun menjadi lebih kecil dan mengeriting)

$m_{4}\{P 01\}=0,6$

$m_{4}\{P 01\}=1-0,6=0,4$

Menghitung kembali nilai densitas baru untuk setiap himpunan bagian fungsi dengan fungsi densitas $m_{5}$. Aturan kombinasi untuk $m_{5}$ seperti Tabel 3 .

Tabel 3. Fungsi Densitas $m_{5}$

\begin{tabular}{ccc}
\hline & $m_{4}\{P 01\}=0,6$ & $m_{4}\{\theta\}=0,4$ \\
$m_{3}\{P 01\}=0,52$ & $\{P 01\}=0,312$ & $\{P 01\}=0,208$ \\
$m_{3}\{\Theta\}=0,48$ & $\{P 01\}=0,288$ & $\{\Theta\}=0,192$ \\
\hline
\end{tabular}

Maka:

$m_{5}(P 01)=\frac{0,312+0,288+0,208}{1-0}=0,808$

$m_{5}(\theta)=\frac{0,192}{1-0}=0,192$

Gejala 4 (G04= Daun rontok, tinggal ranting)

$m_{6}\{P 01\}=0,8$

$m_{6}\{P 01\}=1-0,8=0,2$

Menghitung kembali nilai densitas baru untuk setiap himpunan bagian fungsi dengan fungsi densitas $m_{7}$. Aturan kombinasi untuk $m_{7}$ seperti Tabel 4 .

Tabel 4. Fungsi Densitas $m_{7}$

\begin{tabular}{ccc} 
& $m_{6}\{P 01\}=0,8$ & $m_{6}\{\Theta\}=0,2$ \\
$m_{5}\{P 01\}=0,808$ & $\{P 01\}=0,646$ & $\{P 01\}=0,162$ \\
$m_{5}\{\theta\}=0,192$ & $\{P 01\}=0,154$ & $\{\Theta\}=0,038$ \\
\hline
\end{tabular}

Maka:

$m_{7}(P 01)=\frac{0,646+0,154+0,162}{1-0}=0,962$

$m_{7}(\theta)=\frac{0,038}{1-0}=0,038$

Berdasarkan gejala-gejala yang telah dihitung untuk serangan hama Kutu Hijau (Aphis pomi Geer), nilai densitas yang paling kuat adalah $m_{7}(P 01)$ yaitu sebesar 0,962 atau jika dijadikan prosentasi adalah sebesar $96,2 \%$

REPOSITOR, Vol. 2, No. 1, Januari 2020: 53-66 


\subsection{Implementasi Antarmuka}

Gambar 6 berikut ini diperlihatkan mengenai halaman Identifikasi Hama dan Penyakit Apel seperti pada Gambar 4. Pada halaman ini pengguna akan diharuskan memasukkan data-data yang akan diisi sebelum melanjutkan ke bagian identifikasi. Seperti melakukan pengisian pada kolom nama, melakukan pengisian alamat pengguna pada kolom alamat, setelah itu menentukan letak kebun yang akan di identifikasi pada google map, serta mengisi berapa jumlah pohon yang terserang oleh hama atau penyakit yang akan di identifikasi.
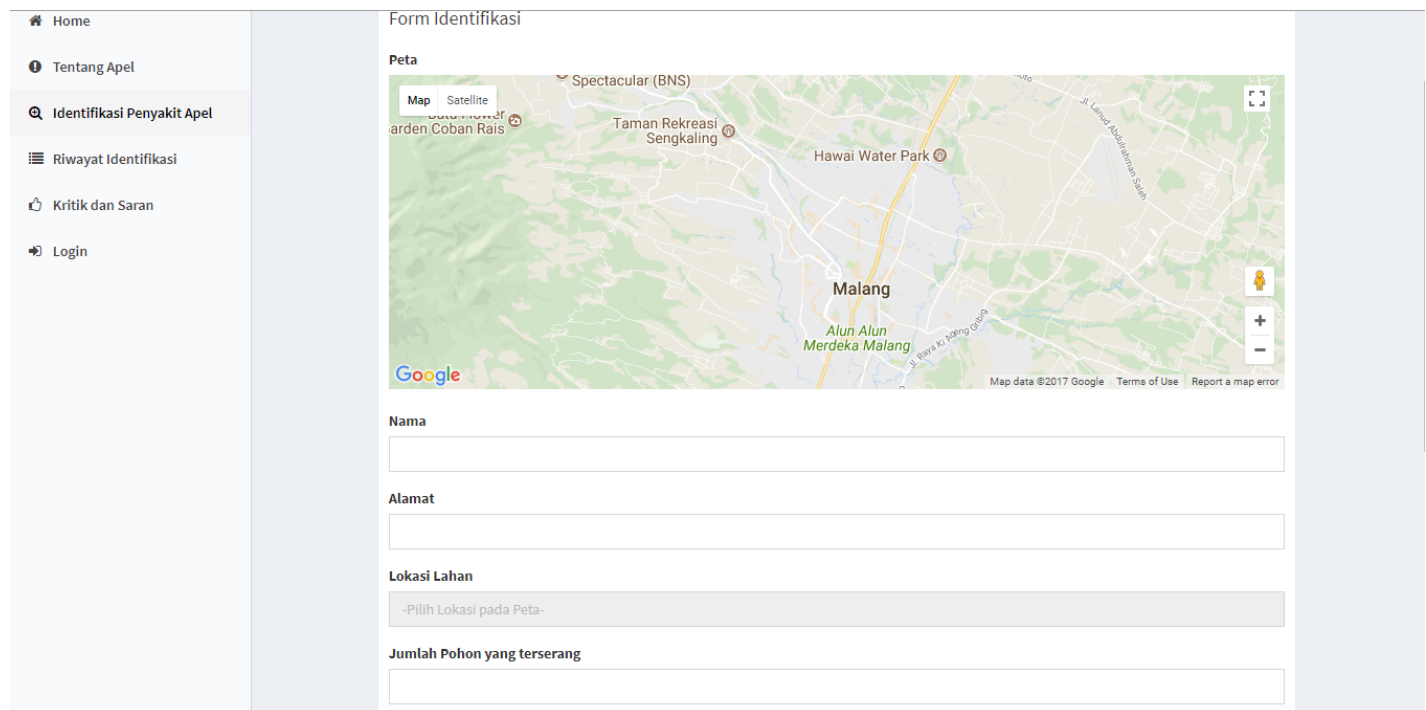

Gambar 6. Tampilan Awal Halaman Identifikasi

Setelah pengguna selesai melakukan pengisian data diawal tadi, akan dilanjutkan dengan pengisian data gejala yang benar-benar dialami oleh tanaman apel yang dimiliki oleh si pengguna. Cara mengisinya cukup mudah, hanya melakukan checklist pada beberapa gejala, kemudian bisa dipilih bagian mana yang akan dipilih seperti ditampilan ada terlihat bagian daun, batang dan juga buah. Setelah selesai maka akan diteruskan dengan menekan tombol "Proses Identifikasi".
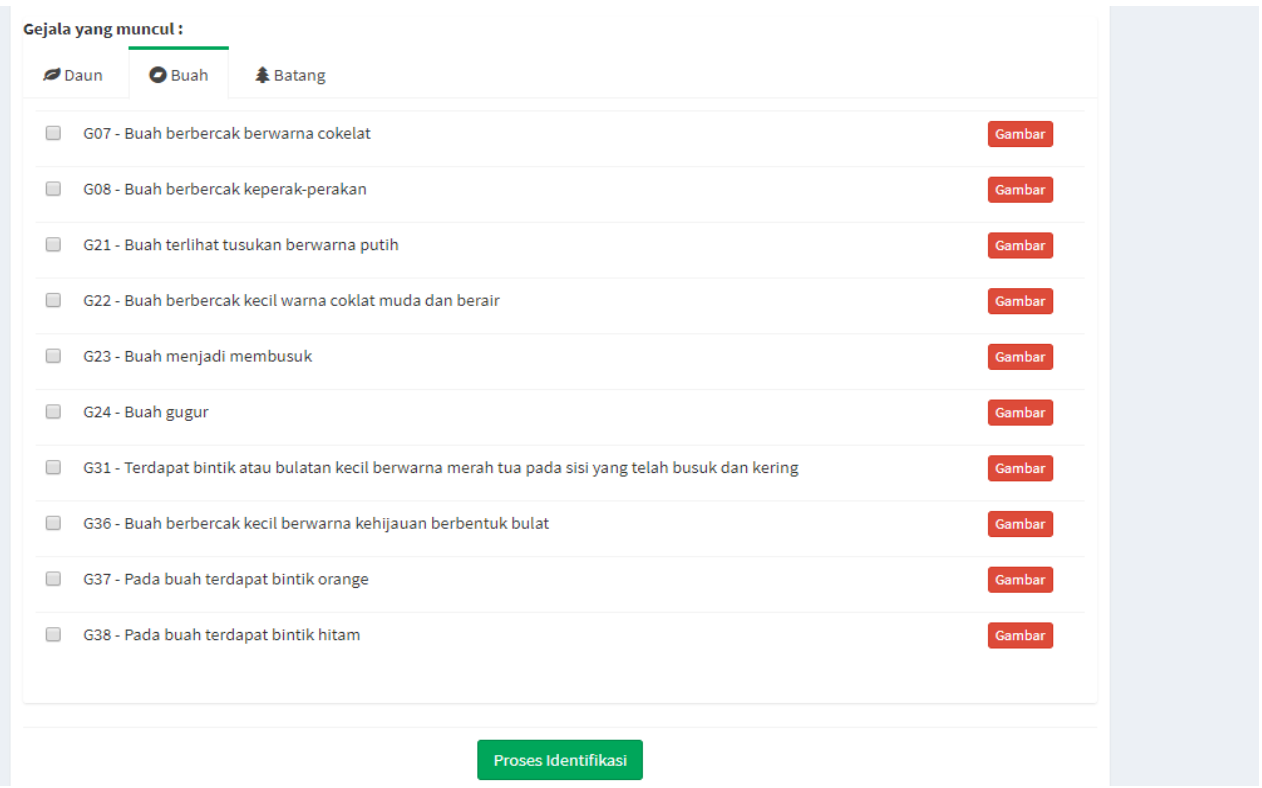

Gambar 7. Tampilan Lanjutan Halaman Identifikasi

Gambar 7 menunjukkan, setelah pengguna menekan tombol "Proses Identifikasi" maka akan lanjut ke halaman hasil identifikasi yang terlihat pada Gambar 5. Isi dari halaman ini adalah 
hasil identifikasi dari inputan pengguna sebelumnya seperti data dan gejala-gejala, menampilkan penentuan penyakit apa yang menyerang tamanan tersebut, menampilkan seberapa persen kemungkinan tanaman tersebut terserang hama atau penyakit, serta menampilkan status tanaman tersebut antara "Aman, "Sedang" atau "Parah" dari serangan hama atau penyakit, dan juga menampilkan solusi agar pengguna bisa cepat menangani tanaman-tanaman apel mereka.

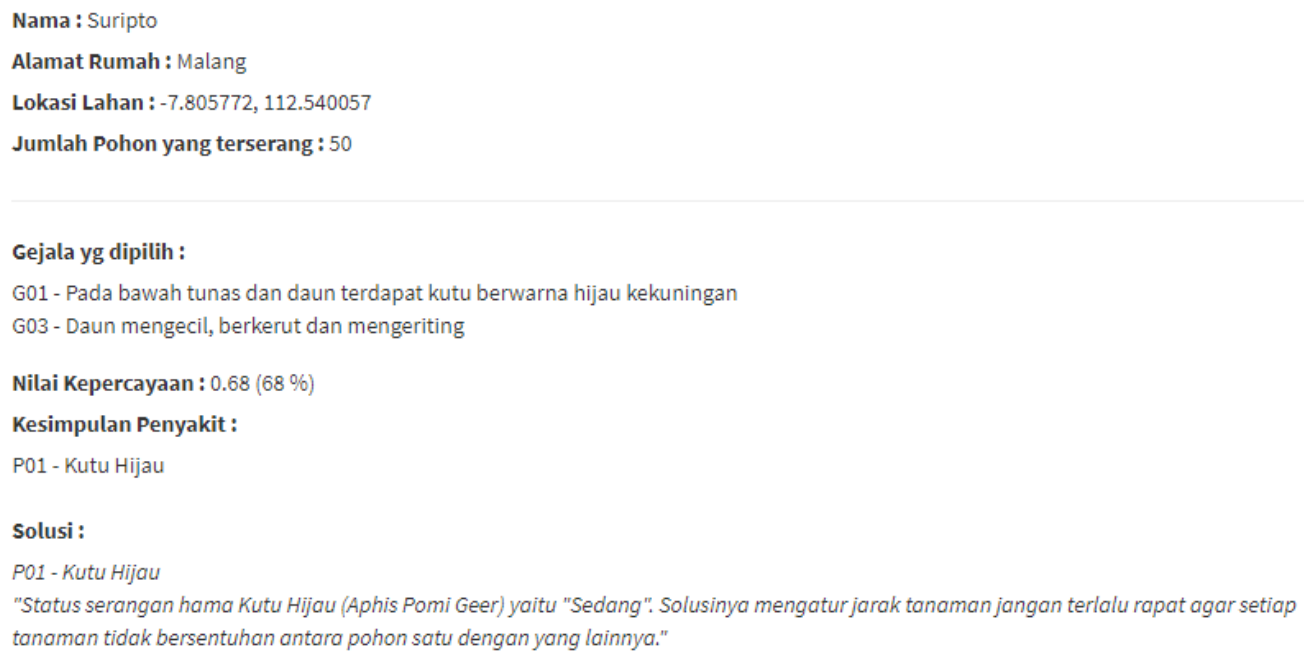

\section{Lihat Perhitungan}

\section{Gambar 8. Tampilan Halaman Hasil Identifikasi}

Selanjutnya juga kita bisa melihat hasil perhitungan pada Gambar 8 menggunakan metode Dempster Shafer dengan menekan tombol "Lihat Perhitungan". Setelah menekan tombol tersebut, maka pengguna akan melihat tampilan seperti Gambar 9.

Perhitungan Dempster Shafer

\begin{tabular}{|l|l|l|l|}
\hline Penyakit & Kode & Gejala & Bobot \\
\hline P01 & G01 & Pada bawah tunas dan daun terdapat kutu berwarna hijau kekuningan & 0.2 \\
\hline P01 & G03 & Daun mengecil, berkerut dan mengeriting & 0.6 \\
\hline
\end{tabular}

Gejala 1 (G01 = Pada bawah tunas dan daun terdapat kutu berwarna hijau kekuningan :

$m 1\{P 01\}=0.2$

$\mathrm{m} 1\{\theta\}=1-0.2$

$\mathrm{m} 1\{\Theta\}=0.8$

Gejala 2 (G03 = Daun mengecil, berkerut dan mengeriting :

$\mathrm{m} 2\{\mathrm{P} 01\}=0.6$

$\mathrm{m} 2\{\theta\}=1-0.0$

$m 2\{\theta\}=0.4$

Menghitung kembali nilai densitas baru untuk setiap himpunan bagian fungsi dengan fungsi densitas $\mathrm{m} 3$.

\begin{tabular}{|l|l|l|}
\hline & $m 2\{P 01\}=0.6$ & $m 2\{\Theta\}=0.4$ \\
\hline$m 1\{P 01\}=0.2$ & $\{P 01\}=0.12$ & $\{P 01\}=0.08$ \\
\hline$m 1\{\Theta\}=0.8$ & $\{P 01\}=0.48$ & $\{\Theta\}=0.32$ \\
\hline
\end{tabular}

Maka
$\mathrm{m}\{\mathrm{P} 01\}=0.68 /(1-0)$

$\mathrm{m} 3\{\mathrm{P} 01\}=0.68 /(1-0)$
$\mathrm{m} 3 \mathrm{P} 01\}=0.68 / 1$

$\mathrm{m} 3\{\mathrm{PO} 1\}=0.68$

Gambar 9. Tampilan Perhitungan Dempster Shafer

REPOSITOR, Vol. 2, No. 1, Januari 2020: 53-66 


\subsection{Pengujian}

Pengujian dalam penelitian ini menggunakan pengujian black box beserta User Acceptance Test (UAT). Pengujian ini berguna untuk membuktikan sejauh mana kesesuaian sistem yang bekerja dengan fungsionalitas dan tujuan perancangan.

\section{a. Pengujian Black Box}

Pengujian fungsional yang sering disebut juga dengan black-box testing yaitu pengujian yang mengabaikan mekanisme internal suatu program dan hanya berfokus pada output aplikasi yang dihasilkan sesuai dengan input serta kondisi yang dipilih [11].

Berikut ini adalah Tabel 5 pengujian black box testing dari hasil implementasi aplikasi yang telah dibuat.

Tabel 5. Hasil Pengujian Black Box

\begin{tabular}{|c|c|c|c|c|}
\hline No. & Fungsi Yang Diuji & Yang Diharapkan & Pengamatan & Hasil Uji \\
\hline 1 & Menu Login & $\begin{array}{l}\text { Menampilkan halaman } \\
\text { Login }\end{array}$ & $\begin{array}{l}\text { Dapat menampilkan } \\
\text { halaman Login }\end{array}$ & Berhasil \\
\hline 2 & Menu Gejala & $\begin{array}{c}\text { Menambahkan, } \\
\text { mengubah dan } \\
\text { menghapus data gejala }\end{array}$ & $\begin{array}{l}\text { Dapat menambahkan, } \\
\text { menghapus dan juga } \\
\text { mengubah data gejala }\end{array}$ & Berhasil \\
\hline 3 & $\begin{array}{l}\text { Menu Hama dan } \\
\text { Penyakit }\end{array}$ & $\begin{array}{c}\text { Menambahkan, } \\
\text { menghapus dan } \\
\text { mengubah data hama } \\
\text { dan penyakit }\end{array}$ & $\begin{array}{l}\text { Dapat menambah, } \\
\text { mengubah dan } \\
\text { menghapus data } \\
\text { hama dan penyakit }\end{array}$ & Berhasil \\
\hline 4 & Menu Solusi & $\begin{array}{l}\text { Menambahkan, } \\
\text { menghapus dan } \\
\text { megubah data solusi }\end{array}$ & $\begin{array}{l}\text { Dapat menambahkan, } \\
\text { menghapus dan } \\
\text { mengubah data solusi }\end{array}$ & Berhasil \\
\hline 5 & Menu Identifikasi & $\begin{array}{l}\text { Menampilkan halaman } \\
\text { identifikasi, } \\
\text { memasukkan data yang } \\
\text { diperlukan }\end{array}$ & $\begin{array}{l}\text { Dapat menghasilkan } \\
\text { informasi keputusan } \\
\text { yang diambil beserta } \\
\text { solusinya }\end{array}$ & Berhasil \\
\hline 6 & $\begin{array}{c}\text { Menu } \\
\text { Perhitungan } \\
\text { Dempster Shafer }\end{array}$ & $\begin{array}{l}\text { Menampilkan proses } \\
\text { perhitungan } \\
\text { menggunakan metode } \\
\text { Dempster Shafer }\end{array}$ & $\begin{array}{c}\text { Dapat menyelesaikan } \\
\text { perhitungan sama } \\
\text { dengan perhitungan } \\
\text { manual }\end{array}$ & Berhasil \\
\hline
\end{tabular}

Berdasarkan hasil pengujian black box pada Tabel 1, dapat didapatkan hasil bahwa dari 7 fungsi yang diuji, seluruh fungsi sesuai atau berhasildijalankan dan dibuktikan dengan data gambar yang sudah diimplementasikan.

\section{b. Pengujian User Acceptance Testing}

Pengujian UAT merupakan pengujian yang mempunyai sudut pandang dari pengguna dari sistem yang sudah dibangun. UAT disini digunakan tidak hanya digunakan untuk pengujian perangkat lunak, namun bisa juga menguji pada kinerja fungsionalitas, keamanan, maupun kegunaan dari system [12]. Pada sistem ini yang dilakukan yaitu pengujian responden dari pengguna dengan pertanyaan sebagai berikut:

1. Apakah sebelumnya anda pernah menjumpai atau menjalankan sistem yang menyerupai sistem pakar untuk mengidentifikasi serangan hama dan penyakit pada tanaman apel?

2. Apakah menurut anda sistem pakar ini mudah digunakan?

3. Apakah menurut anda sistem pakar ini dapat membantu memberikan solusi dari hasil identifikasi serangan hama dan penyakit pada tanaman apel?

4. Apakah setelah ada Sistem pakar ini, anda merasa terbantu dalam mendapatkan informasi dari serangan hama atau penyakit pada tanaman apel?

5. Apakah pada saat sistem ini anda jalankan terdapat kesalahan atau error pada salah satu menu yang disediakan?

6. Menurut saudara, bagaimana penggunaan navigasi atau menu - menu yang tersedia dari aplikasi ini, apakah ada kesulitan dalam penggunaannya?

7. Dari segi isi, apakah informasi yang diberikan oleh sistem pakar untuk mengidentifikasi serangan hama dan penyakit pada tanaman apel sudah lengkap? 
8. Apakah sistem ini dapat membantu tenaga medis untuk identifikasi serangan hama dan penyakit pada tanaman apel?

Tabel 6. Hasil Kuesioner Petani

\begin{tabular}{ccccc}
\hline \multirow{2}{*}{ Pertanyaan } & \multicolumn{4}{c}{ Jawaban Petani } \\
\cline { 2 - 5 } & Ya & Persentase Ya & Tidak & Persentasi Tidak \\
\hline 1 & 0 & $0 \%$ & 10 & $100 \%$ \\
2 & 8 & $80 \%$ & 2 & $20 \%$ \\
3 & 10 & $100 \%$ & 0 & $0 \%$ \\
4 & 10 & $100 \%$ & 0 & $0 \%$ \\
5 & 0 & $0 \%$ & 10 & $100 \%$ \\
6 & 2 & $20 \%$ & 8 & $80 \%$ \\
7 & 7 & $70 \%$ & 3 & $30 \%$ \\
8 & 10 & $100 \%$ & 0 & $0 \%$ \\
\hline
\end{tabular}

Dari data Tabel 6 diatas dapat diberi kesimpulan bahwa:

1. Semua responden belum pernah menemui sistem yang menyerupai dengan sistem pakar ini.

2. Sebagian besar responden memberikan pendapat mereka bahwa sistem pakar ini mudah digunakan dan dapat memberikan informasi tentang hama dan penyakit pada tanaman apel.

3. Sistem pakar ini dapat mengidentifikasi serangan hama atau penyakit pada tanaman apel serta bisa memberikan solusi untuk penanganan serangan hama atau penyakit.

4. Tidak adanya ditemukan error ketika responden menjalankan program.

5. Sistem pakar ini dapat membantu para petani mengidentifikasi serangan hama atau penyakit pada tanaman apel mereka.

6. Identifikasi yang dihasilkan sudah benar den sesuai dengan gejala yang diderita ada tanaman apel.

7. Sistem pakar ini sudah mewakili seorang pakar dalam mengidentifikasi serangan hama atau penyakit pada tanaman apel.

c. Pengujian Akurasi Sistem

Tabel 3. Tabel hasil identifikasi dari Pakar dan Sistem

\begin{tabular}{|c|c|c|c|}
\hline Tanaman Apel & Gejala & $\begin{array}{c}\text { Hasil Identifikasi } \\
\text { Pakar }\end{array}$ & $\begin{array}{l}\text { Hasil Identifikasi } \\
\text { Sistem }\end{array}$ \\
\hline Tanaman A & $\mathrm{G} 01, \mathrm{G} 02, \mathrm{G} 03, \mathrm{G} 04$ & Kutu Hijau & Kutu Hijau \\
\hline Tanaman B & G20, G21, G22, G23 & Lalat Buah & Lalat Buah \\
\hline Tanaman C & G07, G12, G17, G18 & $\begin{array}{c}\text { Serangga } \\
\text { Penghisap Daun }\end{array}$ & $\begin{array}{c}\text { Tungau, Thrips, } \\
\text { Serangga } \\
\text { Penghisap Daun, } \\
\text { Embun Tepung, } \\
\text { Busuk Buah }\end{array}$ \\
\hline Tanaman D & $\begin{array}{c}\text { G29, G30, G31, G32, } \\
\text { G33 }\end{array}$ & Jamur Upas & Jamur Upas \\
\hline Tanaman E & G07, G10, G25, G26 & Embun Tepung & Embun Tepung \\
\hline Tanaman F & $\begin{array}{c}\text { G20, G23, G36, G37, } \\
\text { G38 }\end{array}$ & Busuk Buah & Busuk Buah \\
\hline Tanaman G & G22, G24, G34, G35 & Kanker & Kanker \\
\hline Tanaman $\mathrm{H}$ & G05, G06, G08 & Tungau & Tungau \\
\hline Tanaman I & G36, G37, G38 & Busuk Buah & Busuk Buah \\
\hline Tanaman J & G13, G14, G15 & Ulat Daun & Ulat Daun \\
\hline
\end{tabular}

Batasan masalah dalam pengujian ini adalah, user harus memasukkan gejala lebih dari dua gejala. Karena jika hanya satu gejala yang dipilih, ada kemungkinan yang terpilih adalah gejala yang mempunyai hubungan ke beberapa penyakit.

Tabel37 diatas merupakan hasil identifikasi dari seorang pakar dan hasil identifikasi dari sistem yang menggunakan metode dempster shafer, pada tabel hasil identifikasi terdapat kesamaan pengambilan keputusan dari seorang pakar dengan pengambilan keputusan dari sebuah sistem, ada 10 pengujian yang dilakukan. 9 hasil identifikasi memiliki kesamaan antara

REPOSITOR, Vol. 2, No. 1, Januari 2020: 53-66 
keputusan pakar dengan sistem. Dan ada satu hasil yang berbeda pada tanaman $\mathrm{C}$ keputusan pakar hanya satu yaitu Serangga Penghisap Daun, dan hasil dari sistem ada 4 yaitu Tungau, Thrips, Serangga Penghisap Daun dan Embun Tepung, Busuk Buah. Pada sistem mengeluarkan hasilnya banyak dengan persentasi yang sama dikarenakan oleh pemilihan pergejala yang mempunyai hubungan ke banyak hama atau penyakit atau juga hubungan gejala tersebut lebih dari satu hama atau penyakit.

Dari 10 data diatas dapat disimpulkan bahwa tingkat keakuratan yang dimiliki oleh sistem ini sebesar kurang lebih sebesar $90 \%$.

\section{Kesimpulan}

Untuk hasil penelitian pada laporan ini dapat diberikan kesimpulan seperti dibawah ini :

1. Perancangan software sistem pakar untuk mengidentifikasi serangan dari hama maupun penyakit pada tanaman apel dengan metode yang digunakan yaitu metode Dempster Shafer, Bahasa Pemrograman PHP serta Database MySQL dan berdasarkan pengetahuan dari pakar.

2. Tingkat akurasi yang dihasilkan oleh sistem yaitu $90 \%$ sama dengan tingkat akurasi yang dihasilkan oleh pakar.

3. Hasil pada penelitian ini merupakan sistem pakar untuk mengidentifikasi hama dan penyakit pada tanaman apel sebanyak 7 jenis hama dan terdapat 5 jenis penyakit dengan metode perhitungan yang digunakan yaitu Dempster Shafer untuk mendapatkan hasil odentifikasi berupa nilai kepercayaan dalam bentuk persen dari gejala-gejala yang di inputkan. Berdasarkan hasil dari pengujian ini, sistem dapat digunakan dan membantu petugas lapangan atau pakar yang sedang melakukan observasi perkebunan apel milik para petani ketika petani betanya jika ada gejala-gejala yang menyerang tanaman apel mereka dan mempermudah para pakar menentukan jawaban jika sedang sosialisasi dengan para petani apel. Tidak menutup kemungkinan juga para petani bisa menggunakan aplikasi ininamun dengan bimbingan dari seorang pakar juga.

\section{Referensi}

[1] D. C. Utami, "Analisis Kelayakan Budidaya Apel (Malus Sylvestris Mill) di Desa Bulukerto, Kecamatan Bumiaji, Kota Batu," pp. 45-52.

[2] R. S. Pressman, Software Engineering A Practitioner's Approach 7th Ed - Roger S. Pressman. 2009.

[3] I. Sommerville, Software Engineering. 2010.

[4] H. Listiyono, "Merancang dan Membuat Sistem Pakar," J. Teknol. Inf. Din., vol. XIII, no. 2, pp. 115-124, 2008.

[5] A. Sulistyohati, T. Hidayat, K. Kunci: Ginjal, S. Pakar, and M. Dempster-Shafer, "Aplikasi Sistem Pakar Diagnosa Penyakit Ginjal Dengan Metode Dempster-Shafer," Semin. Nas. Apl. Teknol. Inf., vol. 2008, no. Snati, pp. 1907-5022, 2008.

[6] S. Hartati and S. Iswanti, "Sistem Pakar dan Pengembangannya," Graha IImu, Yogyakarta, 2008.

[7] S. Haris, "Manajemen Database MySQL menggunakan MySQL-Front," PT Elex Media Komputindo, Jakarta, 2003.

[8] B. Sidik, "MySQL Untuk Pengguna, Administrator, dan Pengembang Aplikasi Web," Informatika, Bandung, 2005.

[9] B. Soelarso, Budidaya Apel. Yogyakarta: Kanisius, 1997.

[10] S. Yuni, Analisis dan Perancangan UML (Unified Modelling Language). Yogyakarta: Graha IImu, 2013.

[11] G. J, J. Tsao, H, S, and Y. Wu, Testing and quality assurance for component-based software. Boston: MA: Artech House, 2003.

[12] B. Hambling and V. P. Goethem, User acceptance testing: a step-by-step guide. Swindon: BCS, 2013. 
REPOSITOR, Vol. 2, No. 1, Januari 2020: 53-66 